\title{
Doação de alimentos como ação emergencial de combate à fome - subsídios aos COMSEAS
}

\author{
Maria Cristina Faber Boog ${ }^{1}$
}

Os Conselhos Municipais de Segurança Alimentar - COMSEAs têm por função propor as diretrizes gerais da Política de Segurança Alimentar e Nutricional a serem implementadas pelos órgãos executores. Freqüentemente os membros dos Conselhos Municipais de Segurança Alimentar precisam posicionar-se em relação às ações emergenciais de combate à fome, ou seja, à doação de alimentos (CONSEA, 2006). Vários fatores de ordem técnica e ética precisam ser considerados na tomada de decisão sobre a pertinência ou não de doar alimentos. O ensaio tem por objetivo trazer elementos teóricos que possam subsidiar os membros de COMSEAs na análise de benefícios e malefícios, a curto e longo prazo, de se empreender ações emergenciais.

Palavras-chave: fome-ética; pobreza; programas e políticas de nutrição e alimentação; segurança alimentar.

\section{Food donation as an emergency action in the fight against hunger}

Municipal Councils of Food Security have the function of proposing general guidelines of Food and Nutrition Security Policy by the executive bodies. Frequently, their members have to deal with such emergency actions as food donations to fight hunger. Different technical and ethical factors have to be kept in mind in the decision about the properness of food donation. This essay has the objective of presenting theoretical elements to support the members of Municipal Councils of Food Security in the analyses of benefits and negative consequences in the short and long terms of undertaking such emergency actions.

Keywords: hunger-ethics; poverty; nutrition programs and policies; food security.

\section{Introdução}

Os Conselhos Municipais de Segurança Alimentar - COMSEAs têm por função propor as diretrizes para implantar a política local de segurança alimentar e nutricional, em sintonia com as diretrizes traçadas pelos conselhos estadual e nacional; orientar a implantação de programas sociais ligados à alimentação, estabelecendo diretrizes e prioridades, e articular a participação da sociedade civil. Os Conselhos são compostos por $1 / 3$ de representantes governamentais de áreas afins à temática da segurança alimentar e 2/3 da sociedade civil. Entre várias outras tarefas, cabe aos seus membros orientar as ações emergenciais de doações e assistência imediata a grupos em situação de insegurança alimentar. Por ser uma questão complexa, pouco estudada, que envolve aspectos éticos importantes, foi elaborado o presente ensaio, por meio do qual são apresentadas considerações que visam ampliar a discussão sobre a pertinência de ações emergenciais, ou seja, doações e assistência imediata a grupos em situação de insegurança alimentar (CONSEA, 2004).

O fim último de todas as ações dos Conselhos de Segurança Alimentar de âmbito nacional, estadual ou municipal deve ser a efetiva garantia da segurança alimentar e nutricional conforme definido na II

Professora Dra. da Universidade Estadual de Campinas -UNICAMP /Faculdade de Ciências Médicas do Depto Enfermagem. Pesquisadora do Núcleo de Estudos e Pesquisas em Alimentação - NEPA / Universidade Estadual de Campinas - UNICAMP

E-mail: crisboog@,fcm.unicamp.br ; cristinaboog@hotmail.com 
Conferência Nacional de Segurança Alimentar:

"Segurança alimentar e nutricional é a realização do direito de todos ao acesso regular epermanente de alimentos de qualidade, em quantidade suficiente, sem comprometer o acesso a outras necessidades essenciais, tendo como base práticas promotoras da saúde, que respeitem a diversidade cultural, e que sejam social, econômica e ambientalmente sustentáveis." (CONSEA, 2004)

Conforme a definição acima, a realização da segurança alimentar e nutricional prevê o acesso regular e permanente aos alimentos, de forma que a sua obtenção por intermédio de doações tem um caráter apenas emergencial, e os alimentos devem chegar aos beneficiários que se encontram em situação de risco por meio de creches, asilos, hospitais, associações sociais ou outras instituições. É fundamental que haja controle social sobre todo o processo de doação, recepção e distribuição de alimentos para evitar o desvirtuamento dessas iniciativas que podem vir a servir a interesses particulares. Considerando a multiplicidade de fatores envolvidos na tomada de decisão sobre a doação de alimentos, buscaram-se, na literatura, algumas reflexões, bem como resultados de avaliações que pudessem contribuir para ampliar o contexto sobre o qual se pautam as discussões e decisões acerca da doação de alimentos.

Dar alimento a quem tem fome é, a princípio, uma ação de caráter humanístico incontestável. O cidadão ao qual se pedisse opinião sobre ofertar alimentos a quem se vê privado desse direito naturalmente seria favorável, até para não correr o risco de figurar como adversário da caridade, da generosidade (George, 1978) e da plena realização dos direitos humanos fundamentais. Por outro lado, não se pode ignorar o caráter de paternalismo, clientelismo e demagogia, presentes nessas iniciativas (Maluf, 2006), sobretudo em períodos de campanhas eleitorais. São, de fato, muitas as motivações que levam diferentes pessoas e setores da sociedade a empenhar-se em fazer chegar à boca dos excluídos uma certa quantidade de alimentos, de qualidade por vezes discutível, como no caso da doação de sobras de alimentos prontos, que, potencialmente, trazem risco à saúde. Embora exista um amplo material bibliográfico que permite aprofundar essa discussão, não é objetivo deste trabalho fazer uma revisão sobre o tema, mas tão somente apresentar um ensaio que traz alguns elementos teóricos, com a finalidade de subsidiar a reflexão sobre as ações emergenciais de combate à fome.

A alimentação, prática cotidiana das mais simples, é um tema que pode ser analisado por intermédio de saberes de várias áreas do conhecimento, sendo referido na literatura como um tema agregativo e integrador (Flandrin \& Montanari, 1998). Ocupa posição estratégica no sistema de vida e de valores das sociedades, tendo sido referido por Mauss (apud Poulain \& Proença, 2003) como fato social total, por abarcar, de uma só vez, uma complexa gama de variáveis biológicas e culturais, macro e microssociais, fatores de diferentes ordens - econômicos, históricos, religiosos, só para exemplificar alguns dos muitos focos pelos quais se pode olhar o fato alimentar na busca de tentar compreendê-lo em toda a sua extensão. A alimentação humana é uma questão complexa, multidimensional, palavra empregada aqui na concepção que Morin (2001) atribui a ela, afirmando a pertinência do fenômeno alimentar, ao mesmo tempo, aos campos biológico, psíquico, social, afetivo e racional.

A doação de alimentos como ação emergencial contra a fome tornou-se uma ação política a partir da "Ação da Cidadania contra a Fome, a Miséria e pela Vida", empreendida por iniciativa do sociólogo Herbert de Souza, o Betinho, em 1993. Para ele, a campanha tinha três objetivos: o combate à fome, o programa emergencial de empregos e "pensar o Brasil". A ação emergencial proposta na época era apenas o estopim de uma pretensa grande mudança: "Propomos que o combate à miséria seja a principal prioridade da economia. Isso significa virar a economia de cabeça para baixo e as prioridades também" (Folha..., 1993). A mobilização das classes de mais alto poder aquisitivo para dar alimento aos pobres seria apenas uma ação emergencial e simbólica, um gesto fraterno e solidário que, segundo o seu mentor, viria romper a solidão que delimitava o universo dos excluídos. Era propósito, também, conforme entrevista concedida na época, "colocar junto quem quer fazer mudança estrutural com quem quer praticar solidariedade", e ele deu como exemplo disso a disponibilização de grandes quantidades de alimentos recolhidos pela militância política, para serem distribuídos pelos kardecistas que estavam à frente de programas sociais.

Desde então, shows, competições, festivais e outros acontecimentos públicos servem de mote à 
arrecadação de gêneros alimentícios não-perecíveis para serem doados. Quem faz uma doação não sabe exatamente a quem doa, mas isso parece não ser importante, uma vez que tal doação não gera ônus importante para o doador. Se por um lado hoje existe maior mobilização no combate à fome do que existia em 1993, quando começou a campanha, por outro, parece haver um sentimento diferente daquele imaginado inicialmente por Herbert de Souza, que visava encurtar as distâncias e estreitar os laços entre incluídos e excluídos.

\section{O que é fome?}

A fome, tema amplamente discutido, é um vocábulo polissêmico, porquanto políticos, economistas, sanitaristas, assistentes sociais, nutricionistas, professores de ensino fundamental, agentes de saúde, entre muitos outros que militam em áreas que têm interfaces com a questão alimentar, certamente não estarão falando do mesmo assunto, conquanto utilizem a mesma palavra para referir o seu objeto de estudo ou preocupação. Partindo do pressuposto de que uma definição não seria suficiente para conceituá-la a contento, fazemos um caminho inverso, procurando aclará-la a partir de seus contrastes.

Uma questão fundamental é a distinção entre fome, pobreza e desnutrição. A pobreza é mensurada por intermédio da renda, e considera-se que, quem recebe menos de US $\$ 1,08 /$ dia se encontra abaixo da linha da pobreza e não tem renda suficiente para garantir sua segurança alimentar e nutricional (Belik, 2003), ou para a satisfação de suas necessidades humanas elementares (Monteiro, 2003). A desnutrição decorre da ingestão quantitativamente insuficiente de alimentos e qualitativamente inadequada, que leva a um aporte insuficiente de energia e nutrientes. É avaliada por intermédio de medidas antropométricas (peso e altura) e, embora ainda tenhamos que combatê-la no Brasil, a sua prevalência vem sofrendo redução importante nas últimas décadas. A fome que conhecemos no Brasil é a fome crônica, que deriva da ingestão insuficiente de alimentos, por falta de acesso a eles, e traz como conseqüência a desnutrição. É um dado mais difícil de ser mensurado. Recentemente vêm sendo desenvolvidos métodos para avaliar a insegurança alimentar, já que a fome não tem critério de mensuração.
A distinção, embora aparentemente clara, não é, na prática, tão simples. A visão de crianças malvestidas, de pés descalços ou sandálias de borracha, olhar vago e triste, que remete a um sentimento de desesperança, pode sugerir a emergência da fome. Com certeza se estará à frente de um quadro de pobreza, mas não necessariamente de fome, e a desnutrição também pode ou não estar presente. As palavras de Monteiro situam muito bem a questão: "embora igualmente graves e indesejáveis, e ainda que compartilhem causas e vítimas, fome, desnutrição e pobreza não são a mesma coisa" (Monteiro, 2003).

O impulso de ofertar alimento para suprir carências perceptíveis até aos mais céticos não pode ser reprimido, mas cabe compreender e esclarecer os cidadãos e, particularmente, os membros que compõem os COMSEAs, a respeito dos múltiplos fatores presentes nesse quadro tão afeto aos brasileiros de todas as regiões do país. A situação de pobreza reflete uma multiplicidade de condições adversas, responsáveis pela expressão de tristeza e desolação, nem sempre aventadas por quem nunca teve uma proximidade maior com a miséria. Ao lado da baixa renda, outros fatores (diretamente dela decorrentes ou não) configuram o universo desses cidadãos, tais como: habitações insalubres destituídas dos mais primários itens de conforto, como por exemplo uma cama para cada pessoa, telhados e janelas que efetivamente preservem o interior das casas da chuva, vento e frio; prédios escolares em estado precário, pouco atraentes para as crianças; professores mal remunerados, desestimulados para o ensino; grandes distâncias a serem percorridas entre moradia e trabalho, o que reduz as horas de descanso; dificuldade de acesso a assistência médica. Paralelamente a tudo isso, o constante assédio da propaganda, ao criar desejos e incitar as pessoas ao consumo dos mais diversos itens, inclusive os alimentares, confunde consumo com bem-estar e felicidade, e frustra incessantemente quem não tem condições de adquiri-los (Sung, 1997). Em estudo realizado com mulheres alcoolistas, sobre sua história alimentar, foi observada por intermédio dos depoimentos gravados, a distinção que as mulheres faziam entre as expressões "ser pobre", "passar fome" e "passar necessidade". O primeiro reflete uma condição na qual a pessoa experimenta múltiplas carências; "passar fome" caracteriza a ausência dos alimentos necessários à subsistência e "passar necessidade" é a condição em que a pessoa identifica alimentos que ela julga necessários, mas que, rotineira 
ou habitualmente, ela não tem condição econômica para adquirir (Schlichting, 2004).

Freqüentemente, esse quadro complexo é, apressadamente, tomado como falta de alimentos - fome, que seria (facilmente!) saciada pelo fornecimento de gêneros. Evidentemente, a fome é um fator, entre os muitos, que quase sempre, mas não obrigatoriamente, está presente nessa situação de múltiplas carências, mas é, sem dúvida alguma, o aspecto mais fácil de ser tratado de forma emergencial - doando-se alimentos, seja um prato de comida, um "sopão" comunitário, uma cesta básica ou até guloseimas. Dar comida é lícito, é sempre bem-vindo para quem a recebe: supre a fome, economiza-se para comprar outras coisas, doa-se para alguém que precise mais - conforme comprovado em pesquisa que avaliou o destino dado a cestas básicas (Gerhart, 2006) -, promove um convívio social (no caso de alimentos prontos ofertados a comunidades carentes, como o "sopão") e provoca o riso nas crianças quando a doação é uma guloseima. A doação e a recepção de alimentos evocam em quem dá e em quem recebe sentimentos os mais variados, alguns já identificados em trabalhos realizados por autores preocupados com o resgate da cidadania e com a emancipação política das classes pobres (Magalhães, 2002). Em suma, alimento sempre é bem-vindo, ainda que não para saciar a fome, uma vez que sempre haverá outros desejos a serem satisfeitos.

Outro aspecto que merece ser considerado aqui é o "fantasma" da fome pregressa. A fome deixa marcas indeléveis. É como se a possibilidade, ainda que remota, de reencontrar esse fantasma, de depararse novamente com uma situação de penúria tal que inviabilize a alimentação, fosse uma possibilidade real a espreitar a pessoa a cada momento. Cabe trazer aqui as considerações de Freitas (2003) a esse respeito, a partir de estudo com base fenomenológica, realizado no estado da Bahia:

"A ameaça da fome, visualizada como um fantasma, anda colada à experiência dos atores. Esse é um aspecto analisado, por implicar contradições sobre as interpretações da fome instalada no bairro. Tratase de um indicativo do fenômeno, que independe da renda ou da constituição física do corpo. Com essa hipótese de trabalho, observo que o sujeito inserido no contexto social, mesmo sem apresentar sinais orgânicos de fome, continua a pensar e a manter uma relação com o alimento como um faminto." (Freitas, 2003: 24)

"[...] quem experimentou a condição concreta da fome e continua convivendo com semelhantes processos, sentirá sempre o registro da fome em seu íntimo, como um dado que se endereça a uma cultura da fome, presente no bairro." (Freitas, 2003, p.254)

Essas são questões a serem compreendidas por quem se vê na contingência de opinar e deliberar sobre ações sociais e políticas no âmbito da alimentação. A idéia simplista de que o alimento sacia a fome do pobre deve ser analisada com cautela, pois a fome não se apresenta necessariamente na sua forma biológica, embora o alimento doado seja sempre bem-vindo, ainda que nem sempre bem apreciado, porque não é aquele desejado e adquirido por livre escolha.

\section{Generosidade, caridade, solidariedade - ações e contradiçoes}

Dar comida a quem tem fome sempre foi considerado um ato caridoso. Não é difícil arrecadar alimento para distribuí-lo aos mais pobres, pois a menção a pratos vazios, sobretudo quando são pratos pertencentes a famílias com crianças, desperta sentimentos de caridade, solidariedade e, sobretudo, muita generosidade. A té porque muitas vezes o custo do que deve ser doado é pouco significativo no orçamento de quem doa, o que estimula uma generosidade pouco comprometida e favorece uma caridade pouco crítica. Entretanto, é preciso lembrar que a generosidade que sustenta doações pode representar um braço de uma ordem social injusta que, com o outro, mantém a política econômica geradora da fome e as relações espúrias que trazem fome aos países dependentes e até mesmo a trabalhadores assalariados (Boog, 2004). Paradoxalmente, é a mesma ordem social injusta que causa e mantém a desigualdade social e a pobreza, de forma tal que cada vez mais mãos se estendem para receber doações - generosamente ofertadas -,levando a um círculo vicioso de manutenção da pobreza e da generosidade fácil.

A caridade difere da solidariedade, que é realizada no corpo-a-corpo, por entidades de caráter filantrópico, de forma tal que a face de quem oferece é mostrada para quem recebe, e quem recebe pode sentir-se digno, porque sabe que a situação adversa é 
temporária e, por isso, a ajuda é oportuna, necessária e não fere sua dignidade. A distribuição deve obedecer a critérios técnicos e éticos e deve ser realizada mediante avaliação nutricional e identificação de grupos de risco. Aos governantes cabe a implementação de políticas públicas que enfrentem o problema da fome e não sair às ruas distribuindo alimentos, o que já se configura um ato populista e demagógico. Esse é um primeiro ponto a ser considerado pelos COMSEAs: que todo alimento arrecadado seja utilizado ou distribuído por instituições filantrópicas que desenvolvem ações assistenciais diretamente com as pessoas que vão receber os alimentos, de forma que essa oferta seja acompanhada de atitudes fraternas e ações educativas emancipatórias.

Com respeito aos agentes sociais envolvidos nesses trabalhos, também há que se fazer uma consideração de ordem ética. Serve como ponto de partida para esta reflexão o trabalho de Selli e Garrafa (2005), que identificaram três tipos de motivações básicas que levam as pessoas a empreender ações de caráter social na condição de voluntários. Conquanto o objeto do presente ensaio seja um pouco diferente, e não se esteja tratando diretamente do voluntariado, é pertinente resgatar o pensamento e os achados desses autores para pensar sobre a adequação ou não de doar alimentos, bem como estabelecer alguns critérios para tomada de decisão a respeito de quando isso deve ou não ser feito e por quem. No caso estudado por Selli e Garrafa, foram encontradas as seguintes motivações para a realização de ações voluntárias: a) motivações pessoais relacionadas à vida do próprio voluntário; b) motivações decorrentes da crença (religiosa) professada pelo voluntário; c) motivações despertadas pelo sentimento de solidariedade. Para os autores, a solidariedade deve ser exercida criticamente, pois " $\mathrm{O}$ enfrentamento dos problemas sociais supõe articular as disposições governamentais com as iniciativas sociais; os recursos institucionais, com as dinâmicas comunitárias; a competência técnica com a habilidade humana" (Selli e Garrafa, 2005, p.477).

As motivações que impulsionam ações generosas, como trabalho voluntário ou doações, devem ser canalizadas a programas realizados em consonância com políticas assistenciais comprometidas com o resgate da cidadania. A caridade, entendida como sinônimo de compaixão, esmola, favor, é freqüentemente colocada a serviço do assistencialismo, que desmobiliza o potencial de cidadania do assistido, escamoteia o contexto da desigualdade social e provoca a dependência (Demo, 2005). Difere da solidariedade, sentimento que impulsiona homens unidos por vínculo recíproco a se auxiliarem mutuamente, imbuídos da responsabilidade moral entre pessoas, grupos e pela própria humanidade (Ferreira, 1986). Crianças e idosos pobres têm direito à assistência, que não deve ser confundida com o assistencialismo que contribui para a permanência dos problemas sociais na medida em que a ajuda não inclui a busca de soluções para os problemas.

Assim, é necessário que a solidariedade se imponha sobre a caridade, de forma a romper com o mero assistencialismo, descomprometido com a emancipação política dos grupos beneficiados pelos programas sociais. Numa linha de raciocínio paralela, qual seja, a de garantir os direitos de cidadania no exercício de políticas compensatórias de segurança alimentar, Maluf (2006) recomenda que elas contemplem três aspectos: a) educativos, em relação aos hábitos e práticas alimentares; b) organizativos, para a defesa dos direitos de cidadania; c) emancipadores, visando promover a autonomia e não a dependência dos beneficiários. Um segundo ponto, portanto, a ser cuidadosamente analisado pelos COMSEAs, é em relação às motivações subjacentes às doações de alimentos.

\section{Construção da Segurança Alimentar - para além do acesso ao alimento}

Alguns pesquisadores vêm analisando a contribuição do cuidado associado à disponibilidade de alimento em nível doméstico, e afirmam que sua relevância é indissociável da segurança alimentar e da saúde na determinação do estado nutricional das crianças (Martin-Prével, 2002). É por sua mediação que a segurança alimentar e nutricional se efetiva no âmbito doméstico, em termos de quantidade e qualidade. Pode-se salientar, ainda, que é a comensalidade - o "comer junto" - a interação social e também a cultura que humanizam o ato da alimentação, em contraposição à alimentação dos animais (Flandrin \& Montanari, 1998). Assim, o cuidado dispensado à alimentação no ambiente doméstico é tão importante quanto o acesso econômico aos alimentos e à sua disponibilidade intrafamiliar. O estado nutricional das crianças resulta em grande parte dos cuidados a elas dispensados, principalmente pelas mães, sendo que o cuidado inclui desvelo, solicitude, atenção, 
preocupação e inquietação em relação ao outro (Boff, 1999).

É pertinente também pensar no cuidado dispensado pelos agentes sociais aos beneficiários das doações de alimentos. Ao encontro dessa questão vem o trabalho de Magalhães (2002), que analisou os desdobramentos da "Ação da Cidadania contra a Fome e a Miséria e pela Vida". Conforme relata a autora, o movimento conseguiu, logo em seu início, sensibilizar pessoas que nunca haviam participado de ações coletivas ou de ajuda mútua. Após três ou quatro anos, os que permaneceram nos comitês foram aqueles que já tinham uma trajetória em trabalho social. Foi identificada, na fala dos voluntários, uma visão crítica acerca dos rumos do movimento e até mesmo um certo desapontamento com o resultado da campanha, mas apesar disso foi possível contar com a permanência de indivíduos engajados desde o início, que tinham uma percepção aguçada das questões envolvidas. Conforme diz a autora: "uma perspectiva generalizada de que a pobreza ultrapassa a dimensão da fome, enquanto experiência ligada à sobrevivência física. Ou seja, a pobreza representava diferentes privações, irredutíveis em uma só dimensão" (Magalhães, 2002; 130). A essa visão mais crítica, somavam-se práticas que iam além da doação de alimentos, permeadas por sentimentos que se podem considerar identificados com o cuidado com as pessoas que eram atendidas. Nesse estágio sim, concretizava-se a meta de Herbert de Souza, quando então:

“[...] a dádiva unilateral, da doação de alimentos a desconhecidos em redes amplas e extremamente abertas nas quais o doador não chega a ter contato com o receptor, embora estimulada no início da Campanha, aos poucos é redefinida em práticas que visam criar algum tipo de elo entre quem dá e quem recebe ajuda.” (Magalhães, 2002, p.135)

A possibilidade de ações emergenciais de combate à fome precisa, portanto, ser considerada sob os vários aspectos apresentados. Além do fato objetivo de que o alimento sacia a fome imediata, justificativa para a defesa da estratégia de doação, sob a alegação de que "a fome não espera", é necessário pesquisar e compreender, na perspectiva da subjetividade do sujeito que recebe a doação, que repercussões essa ação tem sobre sua vida e sobre o sentido de cidadania. É preciso atentar para o fato de que as práticas de distribuição de alimentos são portadoras, além do objeto concreto de doação - o alimento - de um conteúdo simbólico, vinculado ao processo de legitimar relações assimétricas de poder (Traverso-Yepez \& Morais, 2004). Quem detém a riqueza e o poder dá - quando quer e como quer - e ao pobre resta passivamente receber e agradecer a "generosidade".

Uchimura e Bosi (2004), analisando dois programas sociais na área de alimentação, alertam para a repercussão que medidas de caráter assistencialista têm sobre a identidade social do pobre, reforçando e reafirmando condições de sujeição: resignação, decepção, constrangimento, tristeza, sofrimento, humilhação, desamparo e discriminação, percebidas na condição de "ser usuário" de tais programas. As autoras concluem que os achados reforçam a necessidade de se considerar a subjetividade que permeia as práticas sociais e recomendam uma efetiva interlocução entre os setores responsáveis pelo planejamento e implantação de programas sociais e a população a que se destinam.

E, finalmente, é preciso considerar que nas várias instâncias de poder se utilizam os meios que se têm à disposição em busca de vantagens econômicas para si e para promover os seus próprios objetivos. Assim, não é possível desconsiderar benefícios advindos para determinados setores da economia ou do governo, de doar alimentos à população. Mais grave a questão se torna quando começam a ser criadas estruturas - de armazenamento, transporte e distribuição (exploradas pela iniciativa privada, mas custeadas pelo Estado) - visando fazer o alimento sair dos setores onde há fartura e sobra, para chegar onde há miséria e fome, o que sugere uma face da indústria da fome denunciada por George (1978).

\section{Conclusão}

Se por um lado "a fome não espera", por outro já se esperou mais de quinhentos anos pela emancipação política e pleno gozo de direitos do povo brasileiro. As repercussões adversas de políticas assistencialistas, que ao longo do tempo geram sujeição e conformismo, forjando um cidadão conformado com seu status quo, precisam ser consideradas pelos COMSEAs. Aos seus membros ficam os dilemas técnicos e éticos que não têm uma única resposta. A decisão em cada situação e em cada localidade só pode ser tomada após ampla discussão, embasada em informações de 
ordem técnica e ética, na consciência de que sempre se pode estar errando, mas também sempre se pode voltar atrás e, com humildade, acertar a partir de novas informações, experiências e reflexões. As experiências em Conselhos Municipais ainda são novas e requerem avaliações e estudos aprofundados.

\section{Referências Bibliográficas}

Belik W. Como as empresas podem apoiar e participar do combate à fome. São Paulo: Instituto Ethos; 2003.

Boff L. Saber cuidar: ética do humano, compaixão pela terra. Petrópolis: Vozes; 1999.

Boog MCF. Contribuições da educação nutricional à construção da segurança alimentar. Saúde Rev. 2004; 6: 17-23.

Conselho Nacional de Segurança Alimentar. Fome Zero. Brasília: Palácio do Planalto. Disponível em: http://www.fomezero.gov.br/download/ CartilhaCONSEAcomp.pdf. Acesso em 5 jun. 2006.

Conselho Nacional de Segurança Alimentar e Nutricional. Princípios e diretrizes de uma política de segurança alimentar e nutricional. Brasília: CONSEA; 2004.

Demo P. Política social, educação e cidadania. 8.ed. Campinas: Papirus; 2005.

Ferreira, ABH Novo dicionário da língua portuguesa. 2.ed. Rio de Janeiro: Nova Fronteira; 1986.

Flandrin JL \& Montanari M. História da alimentação. São Paulo: Estação Liberdade; 1998.

Folha de S. Paulo Combate à miséria é prioridade, diz Betinho. 5 set.1993. Caderno 1: 14.

Freitas MCS. Agonia da Fome. Salvador: EDUFBA / Rio de Janeiro: FIOCRUZ; 2003.

George S. O mercado da fome: as verdadeiras razões da fome no mundo. Rio de Janeiro: Paz \& Terra; 1978.
Gerhardt TE Situações de vida, pobreza e saúde: estratégias alimentares e práticas sociais no meio urbano. Ciên Saúde Colet 2003; 8. Disponível em: www.scielo.br. Acesso em 20 fev. 2004.

Magalhães R. Enfrentando a pobreza, reconstruindo vínculos sociais: as lições da Ação da Cidadania contra a Fome, a Miséria e pela Vida. Cad. Saúde Pública. 2002; 18: 121-37.

Maluf R. Ações públicas de segurança alimentar para grupos populacionais específicos. São Paulo: Instituto Pólis. Disponível em: http://www.polis.org.br/obras/ arquivo 175.pdf. Acesso em 28 fev. 2006.

Martin-Prével Y. Soins et nutrition publique. Santé. 2002; 12: 86-93.

Monteiro CA. A dimensão da pobreza, da desnutrição e da fome no Brasil. Estudos Avançados. 2003; 17: 7-20.

Morin E. Os sete saberes necessários à educação do futuro. 3.ed. São Paulo: Cortez/Brasília: UNESCO; 2001.

Poulain JP \& Proença RPC. O espaço social alimentar: um instrumento para o estudo dos modelos alimentares. Rev. Nutr. 2003; 16: 245-56.

Schlichting S. Almoço como momento terapêutico: uma abordagem de educação em saúde com mulheres alcoolistas [dissertação]. Campinas: Universidade estadual de Campinas; 2004. 98p.

Selli L \& Garrafa V. Bioética, solidariedade crítica e voluntariado orgânico Rev Saúde Pública 2005; 39: 4738.

Sung JM. Desejo, mercado e religião. 2.ed. Petrópolis: Vozes; 1997.

Traverso-Yepez M \& Morais NA. Reivindicando a subjetividade dos usuários da Rede Básica de saúde: para uma humanização no atendimento. Cad. Saúde Pública. 2004; 20: 80-8.

Uchimura KU, Bosi MLM. O mercado dos pobres: um enfoque qualitativo da utilização de programas sociais de alimentação. Cad. Saúde Pública. 2004; 20: 482-91. 